\title{
The Macroeconomic Effect of Public Investment
}

\author{
Chen He \\ School of Economics, Jinan University, Guangzhou, China \\ Email: hchensy@163.com
}

How to cite this paper: He, C. (2017) The Macroeconomic Effect of Public Investment. Modern Economy, 8, 1272-1290. https://doi.org/10.4236/me.2017.811086

Received: October 9, 2017

Accepted: November 7, 2017

Published: November 10, 2017

Copyright $\odot 2017$ by author and Scientific Research Publishing Inc. This work is licensed under the Creative Commons Attribution International License (CC BY 4.0).

http://creativecommons.org/licenses/by/4.0/

\begin{abstract}
This paper establishes a VAR model and VEC model using the data of Chinese public investment, GDP, private investment and employment from 1997 to 2013 aiming to analyze the influence of Chinese public investment on GDP, private investment and employment through ADF unit root test, Granger causality test, Johansen co-integration test, impulse response function, variance decomposition and other empirical methods. Results show that there is a stable equilibrium relationship among Chinese public investment, GDP, private investment and employment in the long term; Public investment has a positive effect on GDP in the short term, which is not obvious even negative in the long term though; Public investment has a crowding out effect on private investment in the short term, while has a positive impact instead in the long term; The positive influence that public investment has on employment is very weak both in the short term and long term. For the stable and healthy development of social economy, the government should improve the efficiency of public investment by means of controlling the scale, optimizing the structure and strengthening the supervision of public investment; A series of policies should be introduced as well to encourage private investment at the same time.
\end{abstract}

\section{Keywords}

Public Investment, GDP, Private Investment, Employment

\section{Introduction}

The adjustment of public capital investment is one of the common ways for governments to regulate and control the development of social economy. Public capital investment has been proved to be an effective regulating factor of economic development for many times in decades. With time going by, the study on public capital gradually aroused strong interests of scholars and experts from all over the world, but a consistent and highly identified conclusion hasn't been 
drawn according to the current domestic and foreign literature because of the differences which exist in the way to select sample data, research methods and acknowledgements of the scope of public capital on a global scale. For example, public investment in the United States can be divided into four categories according to its ultimate use: investment in education, investment in roads and highways, investment in sewage treatment facilities and investment in public utilities. And the proportions of the four public investments in the United States in 1988 are $20.2 \%, 34.5 \%, 7.5 \%$ and $13.2 \%$ respectively [1]. While the scope of public investment in Japan is much wider, which includes 14 different investments. After further classification, it can be considered as investment in education, investment in infrastructure sector, investment in state-owned land and investment in farming and fishing. And the proportions of the four public investments in Japan in 1990 are $12.1 \%, 60.6 \%, 13.5 \%$ and $13.7 \%$ respectively [2].

At present, some researches approve that the increase of public capital investment can effectively promote economic growth, but there are also studies suggest that the adjustment of the scale of public capital investment has no significant effect on the economic output and an inhibiting effect even has been confirmed; Moreover, some literatures show that the public capital investment and economic output are two independent variables, between which there isn't any correlation relationship. Similarly, there's no consensus yet about what kind of influence public capital investment has on private investment and the quantity of employment.

Therefore, ascertaining the impact of public capital investment on variables which represent and are closely related to the development of social economy such as GDP, private capital investment and the quantity of employment based on the real and specific situation China is faced with in the process of economic development, and thus coming to a conclusion about how to improve the efficiency and optimize the structure of the public investment according to the results of corresponding empirical analysis has become the first priority of our research on public capital investment at present, which is of great significance for the development of social economy.

\section{Literature Review}

\subsection{Research on the Contribution of Public Investment to Economic Growth}

At present, most foreign studies suggest that public capital investment has a positive effect on economic growth and the effective promotion impact can be demonstrated by means of making public capital included in the production function [3]. More specifically, although the government's unproductive consumption expenditure can only improve the societal well-being to a certain degree, the productive investment expenditure can greatly boost economic growth [4]. Additionally, through continued innovation on the research method by making the investment in public infrastructure a new variable, a conclusion that 
every $1 \%$ increase in public investment in infrastructure will increase GDP by $1 \%$ can be drawn [5]. However, differences in research sample and research method can also lead to an opposite conclusion. The increase in public capital investment could significantly boost economic growth in the short term, while the impact of public investment on economic growth is very weak in the long term according to Picci [6]. Furthermore, public capital investment in roads and the water supply makes no obvious contribution to economic growth, and there is no sufficient evidence to reject the hypothesis that negative effects might even exist [7].

Differences also arose in most of domestic researches on the effect of public investment on GDP. By redefining the scope of public investment, most researches agree that public investment is a key element of economic growth [8]. Furtherly, taking account of the structure of social economy, the pull effect public investment has on the output of tertiary industry is the most obvious, and the influence on the output of primary industry is the weakest [9]. However, there are also studies suggest that although public investment could effectively stimulate GDP, this impact is not statistically significant and a lasting effect of public capital on economy doesn't exist [10] [11]. In addition, a nonlinear dual threshold effect exists between public investment and economic growth according to $\mathrm{Wu}$ and Yang. When the per capita stock of public investment is lower than the first threshold of 1.834, the increase in public investment has an inhibition effect on economic growth; when the per capita stock of public investment is between 1.834 and 4.261 (the second threshold), the increase in public investment has a significantly positive effect on economic growth; when the per capita stock of public investment exceeds the second threshold of 4.261 , the positive promotion effect tends to fade away [12].

\subsection{Research on the Effect of Public Investment on Private Investment}

Whether public investment has an impact on private investment and what kind of influence it accurately is are still beyond our acknowledgement according to the existing foreign literatures. Some researches point out that public capital investment, especially investment in the infrastructure sector, could greatly boost private investment and the scale of private investment will expand with the increase of public investment at the initial stage of economic development [13] [14]. However, there're also scholars claim that public capital investment has an adverse impact both on private investment and economic development and no correlation has been found between them in some circumstances [15].

Different points of view on the effect of public capital investment on private investment exist in domestic academic literatures as well. The crowding out effect public capital investment, especially investment in education, transport, ware-housing, water conservancy and electric power has on private investment has been proved [16] [17]. However, the analysis focused on 11 provinces and 
cities in east China shows that the coefficients on public investment in the areas of infrastructure construction, education, technology, culture and health are all significantly positive in the long term except that the coefficient on public investment in scientific research is significantly negative [18]. It's also popular that both positive and negative effects of public capital investment on private investment exist, but the positive influence plays a dominant role in the long run [19] [20].

\subsection{Research on the Impact of Public Investment on Employment}

It has generated heated discussion regarding the impact of public investment on employment in foreign countries. By deducing the labor demand function from the profit function, a conclusion that the increase in public investment could positively improve employment can be drawn [21]. However, the subsequent studies show that public investment in tradable sector could increase the quantity of employment to a large extent, while public investment in non-tradable sector has a negative effect on employment [22].

The existing domestic studies have not reached a consensus on the question as well. Public investment could greatly boost the quantity of employment in the long term, while a negative effect of public investment on employment exists in the short term according to $\mathrm{Xu}$ and Yang [23]. On the contrary, a significantly negative impact of public investment on employment exists both in the short term and long term according to Zhu and Zeng [24].

From all the studies above, the macroeconomic effect of public investment on any single variable is still inconclusive; Moreover, a more comprehensive conclusion about the effect of public investment on several variables remains to be arrived at; Lastly, the structural differences of public investment are scarcely taken into consideration.

In view of this situation, we attempt to make as comprehensive analysis of public investment as we can along two different dimensions. On the one hand, define the economic effect of public investment on GDP, private investment and employment on the basis of VAR and VEC model; On the other hand, come up with suggestions about whether to increase public investment and how to adjust the proportion of public investment by comparing the contribution rate of public investment and private investment to economic output and employment respectively presented in the results of variance decomposition, which is of great feasibility and practical significance.

\section{Research Approach}

\subsection{VAR Model \& VEC Model}

VAR model is extended by AR model involving only one single variable, and can be applied to analyzing the dynamic relationship among the endogenous variables in a multi-variable time series model. As macroeconomic system is dynamic and stochastic, the research on the influence public capital investment has 
on the development of economy is also a dynamic process. Hence, we establish a vector autoregressive (VAR) model to examine the impact of public capital investment on GDP, private investment and the quantity of employment which represent and are closely related to the development of social economy. The normative mathematical expression and matrix form of a $\operatorname{VAR}(\mathrm{p})$ model are as (1) and (2) respectively:

$$
\begin{gathered}
y_{t}=\Phi_{1} y_{t-1}+\cdots+\Phi_{p} y_{t-p}+H x_{t}+\varepsilon_{t}, t=1,2, \cdots, T \\
\left(\begin{array}{c}
y_{1 t} \\
y_{2 t} \\
\vdots \\
y_{k t}
\end{array}\right)=\Phi_{1}\left(\begin{array}{c}
y_{1 t-1} \\
y_{2 t-1} \\
\vdots \\
y_{k t-1}
\end{array}\right)+\cdots+\Phi_{p}\left(\begin{array}{c}
y_{1 t-p} \\
y_{2 t-p} \\
\vdots \\
y_{k t-p}
\end{array}\right)+H\left(\begin{array}{c}
x_{1 t} \\
x_{2 t} \\
\vdots \\
x_{d t}
\end{array}\right)+\left(\begin{array}{c}
\varepsilon_{1 t} \\
\varepsilon_{2 t} \\
\vdots \\
\varepsilon_{k t}
\end{array}\right), t=1,2, \cdots, T
\end{gathered}
$$

In a further step, through building a VEC model by non-stationary time series with co-integration relationship, we can not only observe the interaction among the variables in the model, but also reduce the probability of model error with the help of error correction term. As an important improvement and extension of VAR model, it is mainly used to approximate the path of each variable as they converge to their long-term stable state. The mathematical expression of VEC model is as follow:

$\Delta Y_{t}=c+B_{1} \Delta Y_{t-1}+B_{2} \Delta Y_{t-2}+\cdots+B_{p-1} \Delta Y_{t-(p-1)}+A_{t-p}+\varepsilon_{t}, B_{i}=-A_{i}(1,2, \cdots, p-1)(3)$

\subsection{Unit Root Test}

In the empirical analysis of the time series model, regression with highly ideal statistical results doesn't mean the truth all the time. The phenomenon of "Pseudo Regression" happens when nonstationary time series are taken into the regression without any treatment and inspection. To make sure the accuracy of our analysis, we must give priority to the unit root test of the time series involved in the model before implementing the empirical operation. In practice, we usually compare the value of ADF with the threshold at a certain significant level to decide whether to reject the null hypothesis, through which if the time series is stable can be defined.

\subsection{Granger Causality Test}

From the description and explanation of "Pseudo Correlation" above, it's easy to know that a causal relationship doesn't exist inevitably between two variables which are significantly correlated with each other. From this point of view, the Granger causality test is necessary in the first place if we want to analyze the inherent relationship between variables in the model precisely. In practice, the test is accomplished by comparing the significance probability of each hypothesis with different significance level to decide whether to reject the null hypothesis at a specific significant level, through which if a granger causality relationship exists between the two variables can be distinguished. 


\subsection{The Impulse Response Function \& Variance Decomposition}

The impulse response function and variance decomposition are two important methods in analysis of VAR model. The former describes the fluctuation of each endogenous variable after it's affected by shocks from itself and other variables in the model; the latter is mainly used to determine the importance of all the shocks from each variable in the model by comparing the contribution rate of these shocks to the fluctuation of each endogenous variable.

\subsection{Johansen Co-Integration Test}

The theory of co-integration puts forward a main idea that whether a long-term stable equilibrium relationship exists among variables in the model totally depends on if there is at least one stable linear combination of these variables. In practice, it's achieved by comparing the statistics of each hypothesis with the threshold at a certain significant level to determine whether to reject the null hypothesis at the given significant level, through which the existence of co-integration relationships among these variables can be examined.

\section{Data and Measurement}

To measure and capture the appearance of economic growth, public investment, private investment and employment, we construct our dataset from the statistical yearbook of People's Republic of China (1997-2013) with the treatment of taking 1997 as the base year (Appendix). The acquisition of the dataset is as follow:

\subsection{Measuring Economic Growth}

It's available to measure the economic growth along several dimensions and the metric we select ultimately is the annual gross domestic product (GDP). One thing we need to note is that the raw data of GDP is only partially informative when the impact of inflation is taken into consideration. For this reason, we adjust the data by scaling gross domestic product by the index of GDP in each year.

\subsection{Measuring Public Investment (GT)}

Public capital investment refers to all the fixed capital investment in the public sector made by the government and other public enterprises [25]. The most common measure of public investment is a simple aggregation of the fixed capital invested in sectors which are defined within the scope of public capital investment. To eliminate the influence of price fluctuation, we adjust the original data by the price index of investment in fixed assets; What's more, in consideration of the disagreement over the statistical caliber caused by the changes in the classification standards of the national economy industry in 2002, we take a further step to make corresponding adjustment to the data for continuity and reliability. 


\subsection{Measuring Private Investment (PT)}

We use the difference between the total amount of social fixed capital investment and the amount of public capital investment as a measure of private investment, and all the data are adjusted by relevant price index to exclude the impact of price fluctuation.

\subsection{Measuring Employment (JY)}

The matric we apply to measuring the quantity of employment is the total population who participate in various economic activities at the end of each year.

It is noteworthy that natural logarithm processing of variables can not only linearize the trend of the time series but also eliminate the multicollinearity of the data without changing the relationship among the variables in the long term. Therefore, we follow most other articles by using the natural logarithm of variables in our empirical analysis. The natural logarithm of the variables in the next chapter is represented by $L G T, L G D P, L P T$ and $L J Y$ respectively.

\section{Empirical Analysis}

\subsection{The VAR Model}

Firstly, establish the $\operatorname{VAR}(\mathrm{p})$ model and select $p=2$, which is determined by the fact that four of the five evaluation indicators (the rule of LR, the rule of FPE, AIC criterion, the rule of SC and the rule of $\mathrm{HQ}$ ) show a best lag period of 2 consistently. The estimation results of the vector autoregressive model are as follows:

$$
\begin{aligned}
{\left[\begin{array}{c}
L G D P_{t} \\
L G T_{t} \\
L P T_{t} \\
L J Y_{t}
\end{array}\right]=} & {\left[\begin{array}{c}
-10.999 \\
67.866 \\
12.477 \\
7.398
\end{array}\right]+\left[\begin{array}{cccc}
1.027 & 0.044 & 0.132 & 0.357 \\
3.921 & 0.248 & -0.828 & 4.944 \\
-0.581 & 0.085 & 0.283 & -3.235 \\
-0.12 & 0.008 & 0.011 & -0.024
\end{array}\right]\left[\begin{array}{c}
L G D P_{t-1} \\
L G T_{t-1} \\
L P T_{t-1} \\
L J Y_{t-1}
\end{array}\right] } \\
& +\left[\begin{array}{cccc}
-0.185 & 0.004 & -0.141 & 0.762 \\
3.449 & -0.425 & -1.807 & -15.244 \\
2.072 & 0.083 & -0.218 & 1.32 \\
0.154 & 0.005 & -0.022 & 0.33
\end{array}\right]\left[\begin{array}{c}
L G D P_{t-2} \\
L G T_{t-2} \\
L P T_{t-2} \\
L J Y_{t-2}
\end{array}\right]+\varepsilon_{t}
\end{aligned}
$$

1) Stability Test and Analysis of the VAR model

The inspection results of the VAR (2) model show that the numerical value of $R^{2}$ is 0.999758 , which indicates good fit of the four estimated equations presented in the model above. At the same time, the relatively small value of AIC and SC also provide complementary proof for the stability of the model. For a more accurate and comprehensive assessment of the stability of the VAR (2) model, unit root test is conducted, as shown in Figure 1:

The point in Figure 1 stands for the inverted AR root and that all the points are within the unit circle demonstrates the stability of the VAR (2) model established by public capital investment, gross domestic product, private investment and the quantity of employment to a large extent. In other words, changes will 
Inverse Roots of AR Characteristic Polynomial

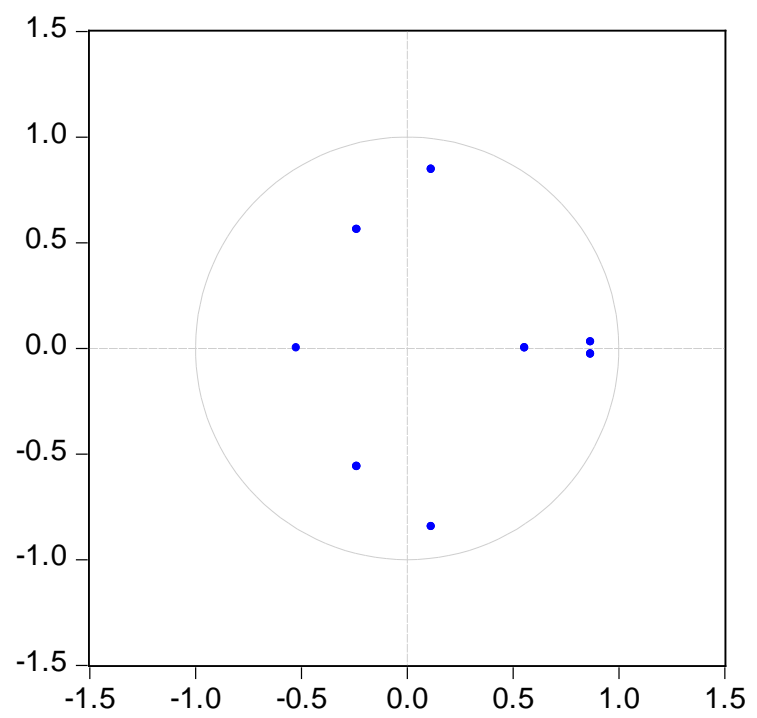

Figure 1. The unit root of AR.

take place in variables in the model as usual when the system is affected by internal shocks, but the impact of the shocks will slowly fade out until the system regains stability.

Through exploration of the VAR (2) model above, it is easy to know:

The influence coefficients of the public investment of lag1 and lag2 to GDP in the VAR (2) model are 0.044 and 0.004 , respectively. It indicates that the lagging value of the public capital investment has a positive impact on economic growth, which is basically consistent with our common sense. On the one hand, as a part of the capital elements, the public capital investment in the production function can produce obvious and direct impact on GDP according to the theory of Cobb Douglas production function; On the other hand, the multiplier effect from the stimulation of the public investment to private investment can bring exponential increase in the total amount of social economic output indirectly according to Keynes's related theory.

The influence coefficients of the public investment of lag1 and lag2 to private investment in the VAR (2) model are 0.085 and 0.083 , respectively. It indicates that the lagging value of the public capital investment has a positive impact on private investment. In fact: the public capital is typically used for infrastructure construction and other basic social public welfare sectors, and thus is of strong positive externalities. On the one hand, the cost of private investment can be reduced to a large extent through the action of "free-rider"; On the other hand, public capital investment can provide a strong backing for risk averters who hold adequate funds, thereby giving impetus to the growth of private investment not only in scale but also in amount.

The influence coefficients of the public capital investment of lag1 and lag2 to employment in the VAR (2) model are 0.008 and 0.005 , respectively, indicating 
that the impact the lagging value of the public capital investment has on employment is not obvious. Although the demand of social economy and the environment of employment can be improved by an increasing public investment apparently, the insignificant impact of the lagging public investment on employment reveals some hidden facts. As a matter of fact, public investment which is mainly focused on social welfare sectors can't provide the economic society with as many jobs as the third industry, and therefore cannot affect the employment market directly and obviously.

The influence coefficients of the gross domestic product, investment of private sector and employment of lag1 to public investment in the VAR (2) model are $3.921,0.828$ and 3.921 respectively. It indicates that GDP, private investment and employment are affected by public capital investment significantly and the improvement of employment, the growth of GDP and private investment all depend on the increase of public capital investment to a large degree. It is consistent with the reality and it also captures the great importance of public investment to the development of social economy.

2) Granger causality test

In this part, Granger Causality Test is employed to explore the relationship among the four variables of public capital investment, gross domestic product, investment of private sector and employment. The results are shown in Table 1:

The following conclusions can be drawn:

At the significance level of 0.05 , there is a two-way causal relationship between LGDP and LPT. That is, private investment is an important factor to affect the growth of GDP and GDP can also affect private investment at the same time, which reflects the real economic relations. In fact, private investment can multiply the economic output through expanding demand and the consequent multiplier effect; at the same time, a higher level of economic output will provide investors in private sector with a good forecast of prospects, thereby encouraging and promoting private investment to a certain extent.

LPT and LGDP constitute the granger cause of LJY at the significance level of 0.05 and 0.1 respectively. That is, both private investment and GDP can significantly affect the quantity of employment. In fact, private investment is mainly focused on the industry that can absorb great quantities of labor force, such as the textile industry, the processing industry and service industry. Hence, increase in private investment can create new jobs for the society directly and thus improve the quantity of employment; at the same time, a high level of economic output can bring such a good forecast of prospects that can attract more investment to the tertiary industry, which can provide workers with new jobs as well.

At the significance level of 0.1, LGT constitutes the granger cause of LPT and LJY, but fails to constitute the granger cause of LGDP. That is, public capital investment can only influence private investment and employment significantly, which is also in line with reality. In fact, increase in public investment can stimulate private investment by reducing the cost and increasing the marginal 
Table 1. Granger Causality Tests of $L G D P, L G T, L P T$ and $L J Y$.

\begin{tabular}{ccc}
\hline Null hypothesis & F-statistic & Prob. \\
\hline$L G T$ is not the Granger cause of $L G D P$ & 1.09769 & 0.3707 \\
$L G D P$ is not the Granger cause of $L G T$ & 2.08799 & 0.1747 \\
$L P T$ is not the Granger cause of $L G D P$ & 4.13097 & $0.0492^{\star *}$ \\
$L G D P$ is not the Granger cause of $L P T$ & 10.0997 & $0.0040^{* *}$ \\
$L J Y$ is not the Granger cause of $L G D P$ & 1.23934 & 0.3305 \\
$L G D P$ is not the Granger cause of $L J Y$ & 4.58143 & $0.0387^{\star *}$ \\
$L P T$ is not the Granger cause of $L G T$ & 1.12686 & 0.3620 \\
$L G T$ is not the Granger cause of $L P T$ & 3.38258 & $0.0755^{*}$ \\
$L J Y$ is not the Granger cause of $L G T$ & 1.34699 & 0.3034 \\
$L G T$ is not the Granger cause of $L J Y$ & 3.32160 & $0.0783^{\star}$ \\
$L J Y$ is not the Granger cause of $L P T$ & 2.72947 & 0.1133 \\
$L P T$ is not the Granger cause of $L J Y$ & 3.80004 & $0.0592^{\star}$ \\
\hline
\end{tabular}

a. ${ }^{\star}$ and ${ }^{* *}$ represent that causal relationship exists at the significance level of 0.1 and 0.05 , respectively.

productivity of private investment through the mechanism of positive externalities; Moreover, it can improve employment by expanding social economic demand; The reason why public investment cannot affect GDP obviously is consistent with our analysis above. Namely, public capital investment cannot provide substantial jobs for labor forces directly, thereby failing to become the granger cause of GDP significantly.

3) Impulse response function

The static relationship among public investment, the gross domestic product (GDP), investment of private sector and employment and the mechanism through which the changes of a variable influence the three other variables in the VAR (2) model have been analyzed. For further exploration of the dynamic relationship among the four variables and especially the influence of shocks from public investment to the three other variables which can reflect the development of economy, the impulse response function is applied, as shown in Figure 2:

According to the diagram:

The first graph in the second column represents the shock of public investment to GDP, and the solid line stands for the post-impact variation trend of GDP. The figure shows that a continuous positive impact of one standard deviation changes in public investment doesn't start to work until the second phase. This kind of positive impact reaches a peak level of 0.016797 in phase 4 , and a lasting commensurate positive response has been maintained. The same as our analysis above, public investment can promote the economic growth by expanding the demand directly and stimulating private investment and technological progress indirectly.

The second graph in the second column represents the variation trend of public investment after it's affected by shocks from itself. The figure shows that the 
Response to Cholesky One S.D. Innovations \pm 2 S.E.

Response of LNGDP to LNGDP

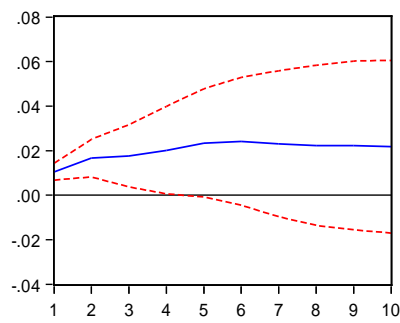

Response of LNGT to LNGDP

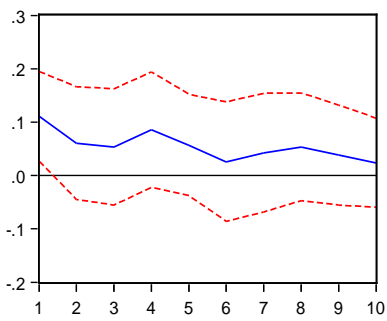

Response of LNPT to LNGDP

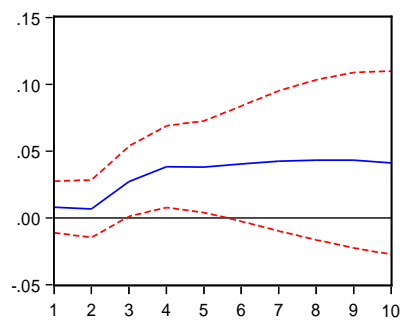

Response of LNJY to LNGDP

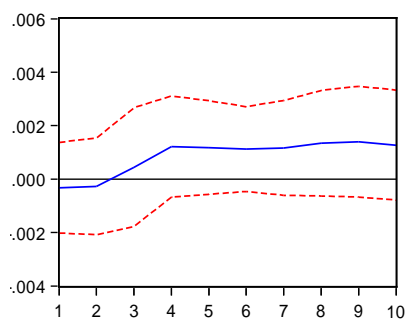

Response of LNGDP to LNGT

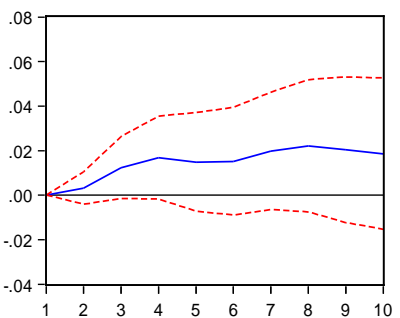

Response of LNGT to LNGT

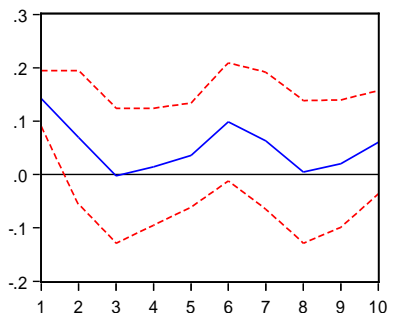

Response of LNPT to LNGT

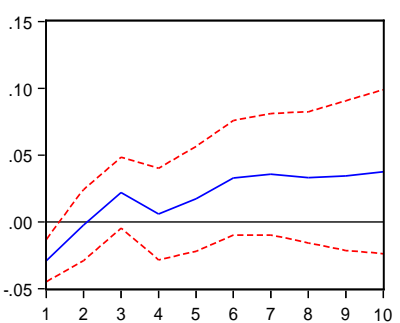

Response of LNJY to LNGT

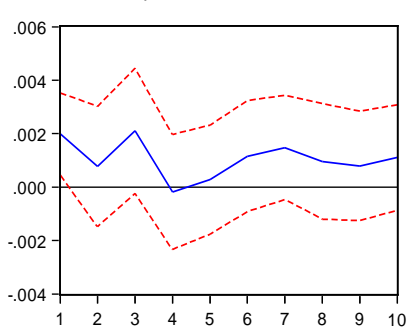

Response of LNGDP to LNPT

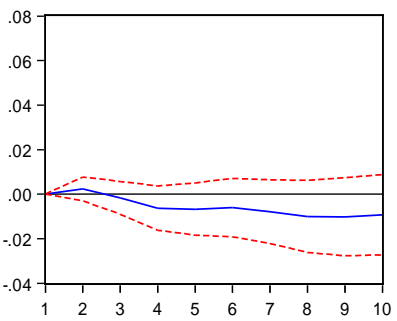

Response of LNGT to LNPT

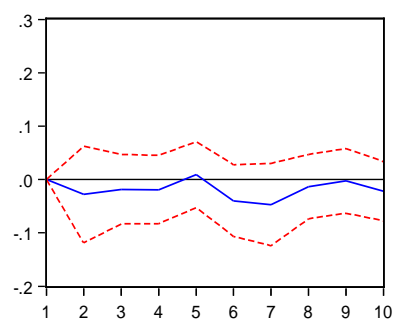

Response of LNPT to LNPT

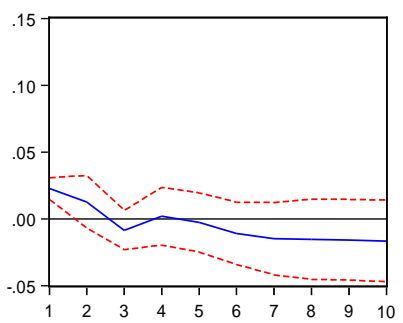

Response of LNJY to LNPT

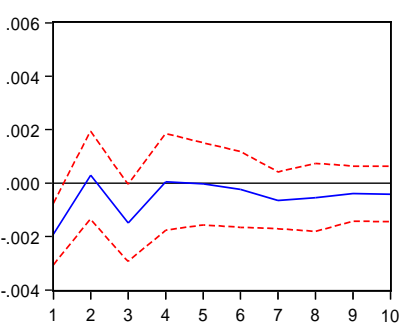

Response of LNGDP to LNJY

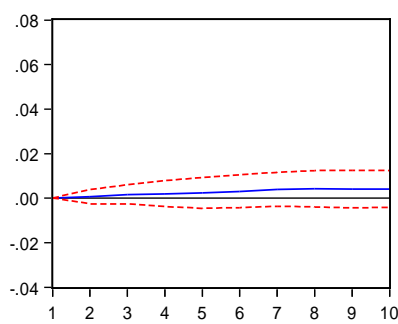

Response of LNGT to LNJY

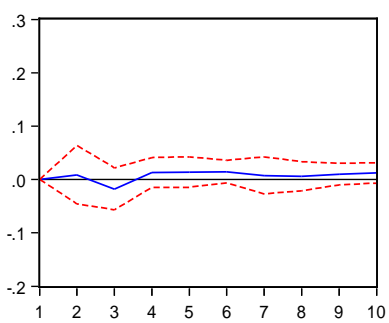

Response of LNPT to LNJY

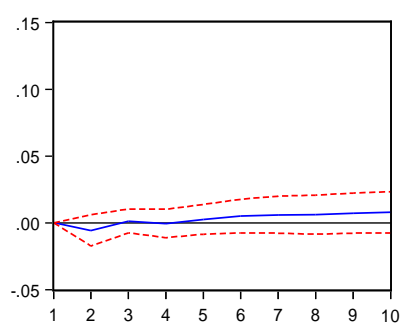

Response of LNJY to LNJY

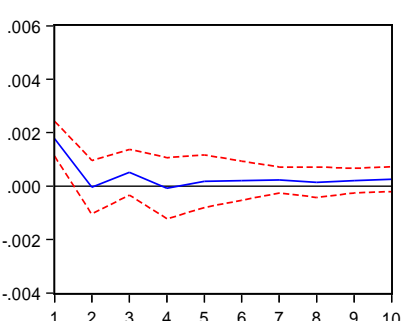

Figure 2. Results of the impulse response function.

Table 2. Variance analysis of $L G D P$.

\begin{tabular}{ccccc}
\hline Period & LGDP & LGT & $L P T$ & LJY \\
\hline 1 & 100.0000 & 0 & 0 & 0 \\
2 & 96.16566 & 2.430365 & 1.304087 & 0.099887 \\
3 & 80.06246 & 18.63377 & 0.956359 & 0.347408 \\
4 & 68.80487 & 27.74109 & 3.036999 & 0.417045 \\
5 & 68.13871 & 27.45970 & 3.908826 & 0.492770 \\
6 & 68.04175 & 27.29830 & 4.013090 & 0.646863 \\
7 & 64.49360 & 30.12143 & 4.528669 & 0.856307 \\
8 & 60.47030 & 33.06142 & 5.467871 & 1.000411 \\
9 & 58.47333 & 34.21288 & 6.224471 & 1.089317 \\
10 & 57.56412 & 34.63330 & 6.624784 & 1.177794 \\
\hline
\end{tabular}


influence of itself is not obvious and the response has been fluctuating around zero, which may be due to the significant decrease of economic efficiency as public investment increases.

The third graph in the second column represents the shock of public capital investment to private investment. As shown in the figure, the negative impact of one standard deviation changes in public investment on private investment starts to fade away until a zero value is acquired in phase 2 and a high level of positive response has been maintained instead in subsequent phases. On the one hand, the fierce competition between the government and private enterprises for the factors of production, funds and projects most of which are basically fixed and limited in the short term composes the main part of the reason why public investment has negative effect on private investment in the short term. For example, the more the government borrows from commercial banks and individual investors, the less social idle funds the private sector can raise through external debt, which obstructs private financing to some extent directly. On the other hand, a high level of positive impact of public investment on private investment in the long term indicates that both positive and negative effect exist at the same time and the positive promotion effect plays a leading role in the long term, though. In fact, in addition to positive externalities, the strong industrial radiation effect of the public capital investment can also stimulate private investment effectively, which is the root cause of the positive effect in the long term.

The fourth graph in the second column represents the response of employment to the shock of public investment. A one standard deviation change in public investment translates into a weak positive response of employment in the whole process, which is also consistent with our analysis above.

4) Variance decomposition

To investigate the contribution rate of public investment to fluctuations of the three other endogenous variables in the model, we carry out the variance decomposition analysis, as shown in Tables 2-4:

From the variance decomposition analysis of LGDP, LPT and LJY in Tables 2-4, following conclusions can be drawn: the impact of public capital investment on GDP has been increasing since the initial stage, but the growth rate starts to decrease from phase 4 . A contribution rate of $34 \%$ is maintained to the end; the impact of public capital investment on private investment has been decreasing rapidly from a high level of $60 \%$ in the initial stage to a minimum level of $26.7 \%$ in phase 5. Despite a small degree of recovery in subsequent phases, an overall level of $33 \%$ to $34 \%$ is maintained to the end; the impact of public investment on employment has been increasing since the initial stage until a maximum level of $47.88 \%$ is reached in phase 3 . A contribution rate of $41 \%-42 \%$ is maintained ultimately. On the one hand, a high level and stable contribution rate of public investment to the fluctuations of GDP, private investment and employment in the long term indicates the nearly optimal explanatory power of public investment in the three other variables in the model in the long run. On the other 
Table 3. Variance analysis of $L P T$.

\begin{tabular}{ccccc}
\hline Period & LGDP & LGT & LPT & LJY \\
\hline 1 & 4.403478 & 59.97445 & 35.62208 & 0 \\
2 & 6.431137 & 51.66299 & 39.93259 & 1.973285 \\
3 & 28.61725 & 45.20205 & 25.01545 & 1.165244 \\
4 & 51.79623 & 30.74704 & 16.67683 & 0.779911 \\
5 & 60.48815 & 26.76580 & 12.09463 & 0.651419 \\
6 & 59.39630 & 30.24808 & 9.633672 & 0.721941 \\
7 & 58.00079 & 32.33685 & 8.856127 & 0.806237 \\
8 & 57.93607 & 32.65902 & 8.537021 & 0.867888 \\
9 & 57.50543 & 33.15683 & 8.357890 & 0.979851 \\
10 & 56.21698 & 34.34127 & 8.337484 & 1.104259 \\
\hline
\end{tabular}

Table 4. Variance analysis of $L J Y$.

\begin{tabular}{ccccc}
\hline Period & LGDP & LGT & LPT & LJY \\
\hline 1 & 1.001419 & 36.28376 & 33.71606 & 28.99876 \\
2 & 1.613129 & 38.99863 & 32.26055 & 27.12769 \\
3 & 2.034787 & 47.88143 & 31.84041 & 18.24338 \\
4 & 9.139398 & 44.47543 & 29.47017 & 16.91500 \\
5 & 14.86718 & 41.77795 & 27.45538 & 15.89950 \\
6 & 18.34654 & 42.65624 & 24.68119 & 14.31603 \\
7 & 20.50693 & 44.30187 & 22.71380 & 12.47739 \\
8 & 24.23360 & 42.93155 & 21.48631 & 11.34855 \\
9 & 27.97261 & 41.27818 & 20.20386 & 10.54535 \\
10 & 29.97229 & 41.16760 & 19.00571 & 9.854390 \\
\hline
\end{tabular}

hand, a higher contribution rate of public investment to economic growth and quantities of employment than private investment also provides us with suggestions that the efficiency of social economy can be improved by enhancing the ratio of public investment reasonably.

\subsection{The VEC model}

1) $\mathrm{ADF}$ test

Stability is the important basis of analysis of time series, so we firstly conduct ADF unit root test to each series in the model. The results are as follows (Table 5):

Although the null hypothesis that at least one unit root exists for the series of LJY is rejected at the significance level of 0.1, sufficient evidence can't be found to reject the null hypothesis of the existence of unit roots for the series of LGDP, LGT and LPT at the same significance level, which means that LGDP, LGT and 
Table 5. Unit root tests of $L G D P, L G T, L P T$ and $L J Y$.

\begin{tabular}{|c|c|c|c|c|c|c|}
\hline \multirow{2}{*}{ Variable } & \multirow{2}{*}{ ADF-value } & \multirow{2}{*}{$\begin{array}{c}\text { Test type } \\
(c, t, k)\end{array}$} & \multicolumn{3}{|c|}{ Test critical values } & \multirow{2}{*}{ Conclusion } \\
\hline & & & $1 \%$ & $5 \%$ & $10 \%$ & \\
\hline$L G D P$ & -2.277916 & $(c, t, 1)$ & -4.728363 & -3.759743 & -3.324976 & Nonstationary \\
\hline$L G T$ & -2.301765 & $(c, t, 0)$ & -4.667883 & -3.733200 & -3.310349 & Nonstationary \\
\hline$L P T$ & -2.645160 & $(c, t, 0)$ & 4.667883 & -3.733200 & -3.310349 & Nonstationary \\
\hline$L J Y$ & -3.686711 & $(c, t, 1)$ & -4.728363 & -3.759743 & -3.324976 & Stationary \\
\hline$d L G D P$ & -1.642008 & $(c, t, 0)$ & -3.959148 & -3.081002 & -2.681330 & Nonstationary \\
\hline$d L G T$ & -4.171532 & $(c, t, 0)$ & -3.959148 & -3.081002 & -2.681330 & Stationary \\
\hline$d L P T$ & -2.759057 & $(c, t, 0)$ & -3.959148 & -3.081002 & -2.681330 & Stationary \\
\hline$d L J Y$ & -4.824687 & $(c, t, 0)$ & -3.959148 & -3.081002 & -2.681330 & Stationary \\
\hline$d d L G D P$ & -3.546937 & $(c, t, 0)$ & -4.004425 & -3.098896 & -2.690439 & Stationary \\
\hline$d d L G T$ & -4.127686 & $(c, t, 1)$ & -4.057910 & -3.119910 & -2.701103 & Stationary \\
\hline$d d L P T$ & -4.506897 & $(c, t, 1)$ & -4.057910 & -3.119910 & -2.701103 & Stationary \\
\hline$d d L J Y$ & -3.692803 & $(c, t, 1)$ & -4.057910 & -3.119910 & -2.701103 & Stationary \\
\hline
\end{tabular}

a. $c, t, k$ represents the constant term, the trend term and the lag length respectively, and $\mathrm{k}$ is determined by AIC criterion; b. d, dd stands for the first and the second order difference of variables respectively.

LPT are all non-stationary time series; Similarly, the conclusion that not all of the first order difference of LGDP, LGT, LPT and LJY (the series of dLGDP, dLGT, dLPT and dLJY) are stationary can be drawn as well; But the ADF-values for the second order difference of series of LGDP, LGT, LPT and LJY (the series of ddLGDP, ddLGT, ddLPT and ddLJY) are all less than the threshold at the significance level of 0.05 , which indicates that ddLGDP, ddLGT, ddLPT and ddLJY are all stationary time series and the series of LGDP, LGT, LPT and LJY can be defined as a I(2) process.

2) Co-integration test

Since the second order difference of the original series are all stationary, co-integration test can be employed to explore the relationship among the four variables in the long term in a further step, as shown in Table 6:

It is easy to know that there are four co-integration relationships among public capital investment, the gross domestic product, investment of private sector and employment at the significance level of 0.05 . Standardized co-integration equations of the four variables are as follows:

$$
\begin{aligned}
& L G D P_{t}=-0.004533 L G T_{t}+0.448033 L P T_{t}+3.373377 L J Y_{t} \\
& \begin{array}{lll}
0.01022) & (0.01144) \quad(0.23029)
\end{array} \\
& L P T_{t}=2.231978 L G D P_{t}+0.010118 L G T_{t}-7.529305 L J Y_{t} \\
& L J Y_{t}=0.296439 L G D P_{t}+0.001344 L G T_{t}-0.132814 L P T_{t}
\end{aligned}
$$

Equation (6) and (7) are the deformation of Equation (5). A long-term stable relationship among public capital investment, GDP, private investment and employment is verified by the equations above. And for every $1 \%$ increase in public 
Table 6. J-J co-integration test.

\begin{tabular}{cccccccc}
\hline $\begin{array}{c}\text { Hypothesized } \\
\text { No. of CE(s) }\end{array}$ & Eigenvalue & $\begin{array}{c}\text { Trace } \\
\text { Statistic }\end{array}$ & $\begin{array}{c}0.05 \\
\text { Critical } \\
\text { Value }\end{array}$ & Prob. & $\begin{array}{c}\text { Max-Eigen } \\
\text { Statistic }\end{array}$ & $\begin{array}{c}0.05 \\
\text { Critical } \\
\text { Value }\end{array}$ & Prob. \\
\hline None $^{* *}$ & 0.950977 & 103.4193 & 47.85613 & 0.0000 & 45.23186 & 27.58434 & 0.0001 \\
At most $1^{* *}$ & 0.917295 & 58.18748 & 29.79707 & 0.0000 & 37.38711 & 21.13162 & 0.0001 \\
At most $2^{* *}$ & 0.613747 & 20.80037 & 15.49471 & 0.0072 & 14.26893 & 14.26460 & 0.0499 \\
At most $3^{* *}$ & 0.353013 & 6.531440 & 3.841466 & 0.0106 & 6.531440 & 3.841466 & 0.0106 \\
\hline
\end{tabular}

capital investment, GDP will decrease by $0.004533 \%$, private investment will increase by $0.010118 \%$ and quantities of employment will increase by $0.0013445 \%$.

3) Analysis of the VEC model

After the confirmation of the long-term co-integration relationship among the four variables, relevant inspections for autocorrelation and heteroscedasticity are carried out as well. Upon testing, phenomenon of autocorrelation and heteroscedasticity in the random error terms are proven to be nonexistent. Given this, a VEC model can be established for further analysis. The error correction term $E C M_{t}$ is as follow:

$$
\begin{aligned}
E C M_{t}= & L G D P_{t-1}+0.004533 L G T_{t-1}-0.448033 L P T_{t-1} \\
& -3.373377 L J Y_{t-1}+30.74768
\end{aligned}
$$

Hereby, the VEC model can be described as follow:

$$
\begin{aligned}
{\left[\begin{array}{c}
\Delta L G D P_{t} \\
\Delta L G T_{t} \\
\Delta L P T_{t} \\
\Delta J Y_{t}
\end{array}\right]=} & {\left[\begin{array}{l}
0.03 \\
0.44 \\
0.23 \\
0.02
\end{array}\right]+\left[\begin{array}{c}
-0.081 \\
2.117 \\
2.097 \\
0.065
\end{array}\right] E C M_{t-1} } \\
& +\left[\begin{array}{cccc}
0.507 & 0.024 & 0.091 & -0.196 \\
-4.027 & -0.142 & 0.728 & 0.913 \\
-1.295 & 0.006 & 0.337 & -0.246 \\
-0.167 & 0.001 & 0.01 & -0.054
\end{array}\right]\left[\begin{array}{c}
\Delta L G D P_{t-1} \\
\Delta L G T_{t-1} \\
\Delta L P T_{t-1} \\
\Delta L J Y_{t-1}
\end{array}\right]+\varepsilon_{t}
\end{aligned}
$$

The value of AIC and SC are -5.368749 and -5.085529 respectively in the model above, both of which are small enough to demonstrate the significance of the established VEC model. From the coefficients of the error correction terms in the model, we can know that change in each variable with the three other variables fixed will increase the unbalanced error by $-8 \%, 1 \%, 211.7 \%, 209.7 \%$ and $211.7 \%$ respectively compared to the previous period.

Through comparison with the preceding co-integration equations we work out, it's easy to know that:

The elasticity coefficient of public capital to GDP equals -0.004533 in the long term, which is negative and the absolute value of which is much less than the coefficient of 0.024 in the short term. It indicates that public capital investment can stimulate the economic growth in the short term, but no obvious promotion effect on GDP exists and a negative effect even works in the long term. The posi- 
tive impact of public investment on GDP in the short term consists of the "Direct Effect" derived from the acceleration to economic demand and the "Indirect Effect" derived from the stimulation to private investment, technical progress and the marginal productivity of the workforce. For this reason, public capital investment tends to play an important role in boosting economy at the initial stage of economic development. Different from the early stage of economic development when public investment in the infrastructure construction area such as roads, railways and airports is still relatively scarce, the increasing public investment in the long term will lead to a large decline in efficiency of itself, which is the root cause of the absence of the positive impact and the existence of the negative impact of public investment on economic growth in the long term.

The elasticity coefficient of public capital to private investment equals 0.010118 in the long term, which exceeds the coefficient of 0.006 in the short term. It indicates that the positive effect of public capital investment on private investment is more significant in the long term. Coincident with our previous analysis, both positive and negative effects of public capital investment on private investment exist and the promotion effect plays a dominant role in the long term.

The elasticity coefficient of public capital to the quantity of employment equals 0.001344 in the long term, which is close to the coefficient in the short term. A positive and near-zero coefficient both in the short term and long term indicates that a weak and positive impact of public investment on employment exists throughout the entire process of economic development. However, the impact can only be a kind of indirect effect because public investment cannot provide the economic society with substantial jobs like investment in the tertiary industry which is determined by its special nature of social welfare.

Lastly, the elasticity coefficient of public investment to the gross domestic product is significantly greater than the coefficient to private investment and employment in the short term. It shows that public investment mainly has an important influence on GDP in the short term, while has a significant effect on private investment in the long term.

\section{Conclusions \& Recommendation}

Through establishing a VAR model and VEC model by Chinese public investment, GDP, private investment and employment, we make an exploration of the relationship among the four variables in depth. Results show that there is a stable equilibrium relationship among public investment, the gross domestic product, private investment and employment in the long term; Public investment has a positive effect on GDP in the short term, which is not obvious even negative in the long term though; Public investment has a crowding out effect on private investment in the short term, while has a positive impact instead in the long term; The positive influence that public investment has on employment is very weak both in the short term and long term; In the long term, for every $1 \%$ in- 
crease in public investment, GDP will decrease by $0.004533 \%$, private investment will increase by $0.010118 \%$ and quantities of employment will increase by $0.0013445 \%$

For the stable and healthy development of social economy, measures should be taken for the government from the following two aspects:

\subsection{Improve the Efficiency of Public Investment}

Firstly, control the scale of public investment reasonably. Although modest increase in public capital investment could accelerate economic growth in the short term, excessive investment of public capital will obstruct the development of economy. Additionally, the inhibiting effect of public investment on the gross domestic product in the long term verified in our empirical analysis also provides evidence for the irrationality of stimulating economic growth by increasing the amount and scale of public investment blindly.

Secondly, define the scope of public investment scientifically and optimize the structure of public investment. Based on the principle that public capital should be focused on areas of infrastructure construction and other basic social public welfare sectors, ambition for vast investment in other industries should be abandoned to avoid excessive interference in social economy. At the same time, corresponding measures to optimize the structure of public investment should be taken to ensure that the limited funds can be put into the field which is most in need of investment in the process of social development, such as areas of energy saving, emissions reduction and ecological environment construction.

Lastly, supervision of the public investment, especially investment in electricity, gas, post, telecommunications and other monopolistic areas should be strengthened to guarantee the timeliness and effectiveness of public investment, reduce the waste of government expenditures and allocate resources properly.

\subsection{Introduce a Series of Policies to Stimulate Private Investment}

The government should try to create favorable investment conditions and build a fair competition environment for private capital. In practice, means of government subsidies and loan with discounted interest can be adopted to stimulate private investment.

\section{References}

[1] Holtz-Eakin, D. and Lovely, M.E. (1995) Scale Economies, Returns to Variety, and the Productivity of Public Infrastructure. Regional Science \& Urban Economics, 26, 105-123. https://doi.org/10.1016/0166-0462(95)02126-4

[2] Shioji, E. (2001) Public Capital and Economic Growth: A Convergence Approach. Journal of Economic Growth, 6, 205-227. https://doi.org/10.1023/A:1011395732433

[3] Arrow, K.J. and Mordecai, K. (1970) Public Investment, the Rate of Return, and Optimal Fiscal Policy. The Johns Hopkins University Press, Baltimore.

[4] Barro, R.J. (1990) Government Spending in a Simple Model of Endogenous Growth. Journal of Political Economy, 98, S103-125. https://doi.org/10.1086/261726 
[5] Futagami, K., Morita, Y. and Shibata, A. (1993) Dynamic Analysis of an Endogenous Growth Model with Public Capital. The Scandinavian Journal of Economics, 95, 607-625. https://doi.org/10.2307/3440914

[6] Picci, L. (1999) Productivity and Infrastructure in the Italian Regions. Giornale Degli Economisti E Annali Di Economia, 58, 329-353.

[7] Evans, P. and Karras, G. (1994) Are Government Activities Productive? Evidence from a Panel of U.S. States. The Review of Economics and Statistics, 76, 1-11. https://doi.org/10.2307/2109821

[8] Yu, C. (2004) The Analysis of Economic Growth and Public Investment of Chinese Government. Economic Science, 103-111.

[9] Yang, D.K. and Sun, M. (2009) The Empirical Study on the Effect of Public Investment on Economic Growth in China. Journal of Shanxi University of Finance and Economics, 8, 34-40.

[10] Wu, P.Z. and Wang, Y.H. (2007) The Analysis of the Impact of Public Investment on Economic Growth. Shandong Social Sciences, 4, 69-72.

[11] Ma, M. (2013) Research on the Economic Effect of Provincial Public Investment Based on the Empirical Analysis of a Panel VAR Model. Technology Economics, 34-70.

[12] $\mathrm{Wu}, \mathrm{N}$. and Yang, F. (2017) The Analysis of the Effect of Public Investment on Economic Growth Based on a Provincial Panel Threshold Model. Prices Monthly, 78-83.

[13] Aschauer, D.A. (1989) Is Public Expenditure Productive. Journal of Monetary Economics, 23, 177-200.

[14] Vijverberg, W.P.M., Chu-Ping, C. and Gamble, J. (1997) Public Capital and Private Productivity. The Review of Economic and Statistics, 79, 67-278. https://doi.org/10.1162/003465397556629

[15] Barth, J. and Cordes, R. (1980) Substitutability Complementarily and the Impact of Government Activity. Journal of Economic and Business, 235-242.

[16] Cao, J., Zhu, B. and Zhao, J. (2005) The Empirical Research on the Relationship among Public Investment, Private Investment and Economic Growth Based on a Vector Error Correction Model. Journal of Hebei University of Economics and Trade, 2, 1-7.

[17] Zhou, Z. and Yang, Y. (2016) The Impact of Public Investment on Private Investment and GDP Based on a SVAR Model. Journal of Jiaxing University, 110-116.

[18] Chen, W. (2014) The Impact of Local Public Capital Expenditure on Private Investment and Its Policy Implications Based on the Empirical Analysis of Eastern China. Reform of the Economic System, 4, 43-47.

[19] Wang, W. (2009) The Analysis of the Crowding out Effect Public Investment Has on Private Investment. Journal of Zhongnan University of Economics and Law, 19-24.

[20] Yuan, D. and Chen, G. (2011) The Regional Difference of the Effect Public Investment Has on Economic Growth Based on the Empirical Analysis of Provincial Panel Data in China. Finance and Trade Economics, 12, 37-45.

[21] Demetriades, P. and Mamuneas, T. (2000) Intertemporal Output and Employment Effects of Public Infrastructure Capital: Evidence from 12 OECD Economics. The Economic Journal, 110, 687-712. https://doi.org/10.1111/1468-0297.00561

[22] Destefanis and Sena (2008) Public Capital, Productivity and Trade Balance: Some 
Evidence for the Italian Regions. Empirical Economics, 37, 533-554.

[23] Xu, X. and Yang, L. (2006) An Explanation of the Effect of Public Investment on the Employment Based on the Analysis and Inspections of the CES Production Function. The Journal of Quantitative and Technical Economics, 11, 94-103.

[24] Zhu, W. and Zeng, Z. (2012) The Research on the Effect of Social Investment on Employment in China Based on a Vector Error Correction Model. Special Zone Economy, 290-292.

[25] Wan, D. and Yang, F. (2011) The Exploration of Defining the Scope of Public Investment in China. Jiangxi Social Sciences, 73-77.

Appendix

\begin{tabular}{ccccc}
\hline Year & GDP* & GT* & PT* & JY** \\
\hline 1997 & 79429.5 & 5526.3 & 18645.3 & 70,800 \\
1998 & 84883.7 & 7305.7 & 20134.5 & 72,087 \\
1999 & 90187.7 & 7649.7 & 21319.4 & 72,791 \\
2000 & 99776.3 & 8349.0 & 23547.8 & 73,992 \\
2001 & 110270.4 & 8751.8 & 27340.1 & 73,884 \\
2002 & 121002.0 & 9127.4 & 32907.8 & 74,492 \\
2003 & 136564.6 & 19104.8 & 35499.7 & 74,911 \\
2004 & 160714.4 & 23903.2 & 45391.6 & 75,290 \\
2005 & 185895.8 & 29599.6 & 57496.4 & 76,120 \\
2006 & 217656.6 & 35194.4 & 72856.0 & 76,315 \\
2007 & 268019.4 & 40298.3 & 94494.9 & 76,531 \\
2008 & 316751.7 & 48622.0 & 120471.5 & 77,046 \\
2009 & 345629.2 & 68520.2 & 150298.9 & 77,510 \\
2010 & 408903.0 & 81691.2 & 189671.7 & 78,388 \\
2011 & 484123.5 & 80730.6 & 225103.3 & 78,579 \\
2012 & 534123.0 & 99668.7 & 275026.0 & 78,894 \\
2013 & 588018.8 & 118998.7 & 327295.4 & 79,300 \\
\hline
\end{tabular}

Data Source: The statistical yearbook of People’s Republic of China (1997-2013). a. ${ }^{\star}$ represents billion yuan and ${ }^{* *}$ represents 10 thousand people. 